\title{
Assessment of Speech Development in Children with Cochlear Implants in Republic of Macedonia Using Monosyllabic-Troche- Polysyllabic Test (Closed-Set)
}

\author{
Vesna Lazarovska ${ }^{1^{\star}}$, Marina Davcheva-Chakar ${ }^{2}$ \\ ${ }^{1}$ Hearing, Speech and Language Rehabilitation Center, Skopje, Republic of Macedonia; ${ }^{2}$ University Clinic for Ear, Nose and \\ Throat, Faculty of Medicine, Ss Cyril and Methodius University of Skopje, Skopje, Republic of Macedonia
}

\begin{abstract}
Citation: Lazarovska V, Davcheva-Chakar M Assessment of Speech Development in Children with Cochlear Implants in Republic of Macedonia Using Monosyllabic-Troche-Polysyllabic Test (Closed-Set) Maced J Med Sci. 2013 June 15; 6(2):153-157. http://dx.doi.org/10.3889/MJMS.1857-5773.2013.0289. Key words: impaired hearing; cochlear implant; speech perception; rehabilitation.

"Correspondence: Vesna Lazarovska, MD, MSc Hearing, Speech and Language Rehabilitation Center, Skopje, Republic of Macedonia. E-mail: vesnalazarovska@yahoo.com

Received: 14-Feb-2013; Accepted: 22-Mar-2013; Online first: 27-Mar-2013

Copyright: @ 2013 Lazarovska V. This is an openaccess article distributed under the terms of the Creative Commons Attribution License, which permits unrestricted use, distribution, and reproduction in any medium, provided the original author and source are credited.

Competing Interests: The authors have declared that no competing interests exist.
\end{abstract}

\begin{abstract}
Background: Electric stimulation of the auditory nerve via cochlear implants has made a great impact on treatment of sensory deafness. Advanced signal processing and stimulation paradigms have led to continuously improved results in speech understanding. Consequently, indication criteria have been extended to patients with profound and severe-to profound hearing loss and limited speech understanding with conventional acoustic amplification.

Aim: The aim of this study was to present speech development in subjects with pre-lingually sensorineural hearing loss implanted with a cochlear implant in Republic of Macedonia.

Methods: The study included 31 subjects of both sexes and pre-lingual sensorineural hearing impairment. The average age of the implanted patients was $100.4 \pm 74.1$ months. The speech perception after cochlear implantation was evaluated using the Monosyllabic-ThrochePolysyllabic test (MTP) with closed-set words without the aid of lip-reading. The patients should be able to point-to or clearly repeat the pictured words (or objects). Subjects were followed-up in a period of 6,12 and 24 month post-implantation.

Results: Cochran's Q-test showed a significant difference in identification of monosyllabic, disyllabic and polysyllabic words in patients with cochlear implant during the analyzed period of 24 months. McNemar's test confirmed that 24 months after implantation the subjects significantly better identified monosyllabic, disyllabic and polysyllabic words in comparison with the time interval at 12 and 6 months. Also, there was a substantial improvement 12 months after cochlear implantation in comparison with the interval at 6 months.
\end{abstract}

\section{Introduction}

Speech development is a highly integrated process encompassing harmonic functioning of several aspects, anatomic-physiological, auditory, mental, emotional and social, so that a child can be able to interpret and understand the sounds used in language.

In subjects with hearing impairment, rehabilitation and therapy are of exceptional importance. Studies have shown that speech perception and production are much better after cochlear implantation [1-3]. Surgical intervention and regular adjustment of the implant are indispensable, but not sufficient in developing complete verbal communication. Speech is a coded linguistic sum of voices in the process of communication. The process of speech development is a gradual learning of the relation between sounds and articulate movements in making those sounds. The earliest weeks and months of normally hearing infants are characterized by reflexive vocalizations such as cooing and babbling. At earliest age the speech is developed and supported primarily by hearing and imitating the sounds. In hearing impaired children the auditory stimulations are weak or they do not exist depending on the degree of the hearing disability. It causes speech impairment since it influences on two fundamental processes: patient's inability to hear the sound of his/her own voice and inability to control 
his/her own speech [4]. The longer the period of stagnation in speech development, the harder is the improvement even with a cochlear implant [5].

In general, children with complete hearing loss cannot develop and understand speech without intensive, systematic and professional treatment with amplifying hearing aids, or their speech understanding is quite unsatisfactory. In cases like these better results are achieved if cochlear implant is implanted.

Speech improvement and development after cochlear implantation has been confirmed by numerous studies which results suggest that cochlear implant increases speech reception and perception skills to a degree that is not possible to be achieved with amplifying hearing aids [6-10].

A total of 57 subjects with cochlear implant have been registered in R. Macedonia by the end of 2012. The first cochlear implantation in R. Macedonia was performed at the University Clinic of Ear, Nose and Throat in Skopje on $7^{\text {th }}$ of April, 2006 by the Academician Prof. Dr. Ilija Filipche and his expert team of otorhinolaryngologists.

A total of 35 subjects were implanted with a cochlear implant at the same Clinic; 25 of them were citizens of Republic of Macedonia and 10 citizens of Kosovo. In August 2012 the first implantation in a subject with a post-lingual hearing impairment was performed.

The aim of this study was to present speech development in subjects with pre-lingually sensorineural hearing loss implanted with a cochlear implant in Republic of Macedonia.

\section{Material and Methods}

The study included 31 subjects with prelingual sensorineural hearing impairment of both sexes and different age. The average age of the implanted patients was $100.4 \pm 75.1$ months. The youngest implanted patient was 10 month old and the oldest was 327 months old. All patients underwent audiometric examination using age appropriate methods: auditory brain-stem responses, otoacoustic emissions and tympanometry. The examinations were carried out at the Audiology Department of the University Ear, Nose and Throat Clinic in Skopje, R. Macedonia. The speech perceptions after cochlear implantations were evaluated using the MonosyllabicTroche-Polysyllabic test with closed-set words without lip-reading [11]. The follow-up period was at 6, 12 and 24 months post-implantation. We used this test to assess the ability of each patient to identify different syllable patterns ranging from one syllable, two syllables, and more than two syllables. We used lists with examples presenting four pictures and words or objects. The speech pathologist pronounced each word from the list at $70 \mathrm{~dB}$ sound pressure via live voice. The test was administered without the aid of lip- reading (hearing only). The patients had to point-to or clearly repeat the words (or objects). We used a list of Macedonian monosyllabic, disyllabic and polysyllabic words. Children with very low linguistic levels were encouraged to make exercises with the items at home helped by the members of the family. This is best accomplished during the preoperative evaluation phase to enable valid baseline data. Each word is uttered once and the child is asked to guess. It may be helpful to use small cards to play a kind of word lotto.

Non-parametric tests, of two or more dependent variables (McNemar's test and Cochran's $\mathrm{Q}$-test) were used for the statistical analysis. A p value $<0.05$ was considered to be statistically significant.

\section{Results}

Table 1 presents the distribution of subjects with cochlear implant $(\mathrm{Cl})$, who can or cannot identify monosyllabic words, at 6, 12 and 24 months following implantation.

Table 1: Test for identification of monosyllabic words (closedset)

\begin{tabular}{|c|c|c|c|c|c|c|c|}
\hline \multirow{2}{*}{\multicolumn{2}{|c|}{$\begin{array}{l}\text { Monosyllabic } \\
\text { words }\end{array}$}} & \multicolumn{2}{|c|}{6 months } & \multicolumn{2}{|c|}{12 months } & \multicolumn{2}{|c|}{24 months } \\
\hline & & \multirow{2}{*}{$\begin{array}{c}\text { number } \\
6\end{array}$} & \multirow{2}{*}{$\begin{array}{c}\% \\
19.4\end{array}$} & \multirow{2}{*}{$\begin{array}{c}\text { number } \\
30\end{array}$} & \multirow{2}{*}{$\begin{array}{c}\% \\
96.8\end{array}$} & \multirow{2}{*}{$\begin{array}{c}\text { number } \\
31\end{array}$} & \multirow{2}{*}{$\begin{array}{c}\% \\
100\end{array}$} \\
\hline & yes & & & & & & \\
\hline (scarf) & no & 25 & 80.6 & 1 & 3.2 & 0 & 0 \\
\hline \multicolumn{6}{|c|}{ Cochran $Q=48.08 \mathrm{df}=2 \mathrm{p}=0.00000$} & \multicolumn{2}{|c|}{$12 / 24$} \\
\hline \multicolumn{8}{|c|}{$6 / 12 \mathrm{McNemar}=22.04 \mathrm{df}=1 \mathrm{p}=0.00000$} \\
\hline \multirow{2}{*}{$\begin{array}{l}\text { nos } \\
\text { (nose) }\end{array}$} & yes & 19 & 61.3 & 29 & 93.5 & 31 & 100 \\
\hline & no & 12 & 38.7 & 2 & 6.5 & 0 & 0 \\
\hline & \multicolumn{5}{|c|}{ Cochran $Q=20.67 d f=2 p=0.000033$} & \multicolumn{2}{|c|}{$/ 12 / 24$} \\
\hline \multicolumn{8}{|c|}{$6 / 12 \mathrm{McNemar}=8.1 \mathrm{df}=1 \mathrm{p}=0.004$} \\
\hline \multirow{3}{*}{$\begin{array}{l}\text { sok } \\
\text { (juice) }\end{array}$} & yes & 17 & 54.8 & 28 & 90.3 & 31 & 100 \\
\hline & no & 14 & 45.2 & 3 & 9.7 & 0 & 0 \\
\hline & \multicolumn{5}{|c|}{ Cochran $\mathrm{Q}=23.29 \mathrm{df}=2 \mathrm{p}=0.000009$} & \multicolumn{2}{|l|}{ / $12 / 24$} \\
\hline \multicolumn{8}{|c|}{$6 / 12$ McNemar=9.09 df=1 $p=0.0026$} \\
\hline \multirow{3}{*}{$\begin{array}{l}\text { stol } \\
\text { (chair) }\end{array}$} & yes & 1 & 3.2 & 18 & 58.1 & 30 & 96.8 \\
\hline & no & 30 & 96.8 & 13 & 41.9 & 1 & 3.2 \\
\hline & \multicolumn{5}{|c|}{ Cochran $Q=43.93 \mathrm{df}=2 \mathrm{p}=0.00000$} & \multicolumn{2}{|c|}{ / $12 / 24$} \\
\hline \multicolumn{8}{|c|}{$\begin{aligned} & 6 / 12 \text { McNemar=15.06 df=1 } p=0.0001 \quad 6 / 24 \text { McNemar=27.03 df=1 } p= 0.00000 \\
& 12 / 24 \text { McNemar }=10.08 d f=1 \quad p=0.0015\end{aligned}$} \\
\hline
\end{tabular}

Six months after $\mathrm{Cl} 19.4 \%$ of examinees identified the word scarf (sal), $61.3 \%$ nose (nos), $54.8 \%$ juice (sok), and only 1 examinee identified the word chair (stol). At the control testing 12 months after $\mathrm{Cl} 96.8 \%$ of examinees identified the word scarf, $93.5 \%$ nose, $90.3 \%$ juice and $58.1 \%$ chair.

Two years after $\mathrm{Cl}$ all examinees pointed to the picture with scarf, nose, and juice, and only 1 examinee could not recognize the picture with the chair. These differences were statistically confirmed.

Cohran's Q-test showed a significant difference in positive and negative results obtained from the Test for identification of the number of 
syllables in monosyllabic words in examinees with $\mathrm{Cl}$ during the analyzed period of 24 months.

McNemar's test showed that 24 months after implantation examinees identified monosyllabic words significantly better than 12 and 6 months following implantation. Also, 12 months after cochlear implantation these words were significantly better identified in comparison with the period at 6 months post-implantation.

Six months after cochlear implantation 5 (16.2\%) examinees were able to identify cap (kapa), $21(67.7 \%)$ baby (bebe), but none of the examinees could recognize cat (macka) or ball (topka). Twelve months after implantation, $21(67.7 \%)$ examinees were able to identify cap, 30 (96.8\%) baby, 9 (29.1\%) cat, and $20(64.5 \%)$ ball. Two years later all of the 31 examinees could identify cap and baby, 24 of them could identify cat, and 29 could identify ball.

In the course of the analysis performed in the 24-month period after cochlear implantation there was a statistically significant difference in the ability of the examinees to identify disyllabic words (Table 2).

Table 2: Test for identification of disyllabic words (closed-set).

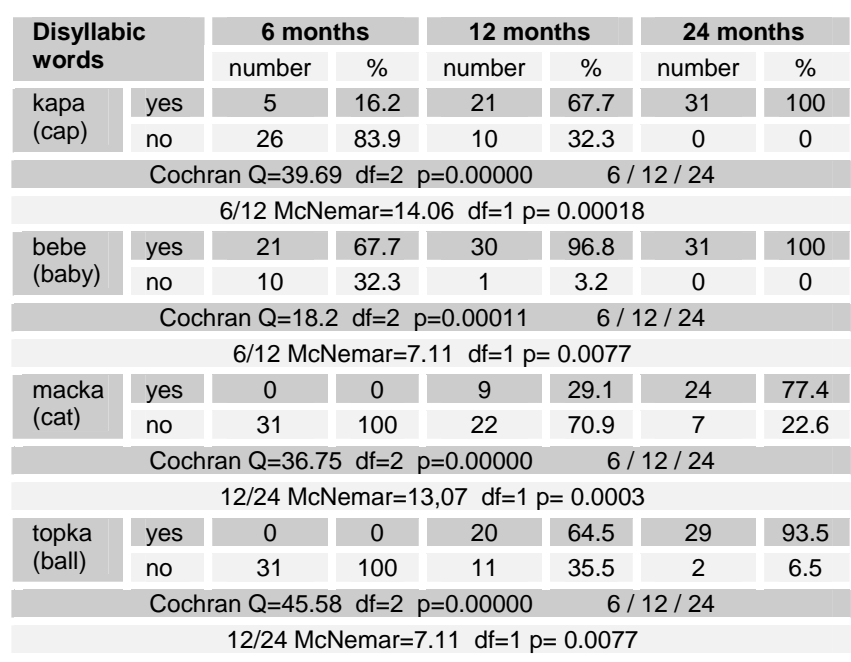

After 24 months of intensive everyday postimplantation rehabilitation and therapy, a statistically significant difference was registered in the ability to identify three-syllable words.

Concerning the identification of polysyllabic words the examinees showed substantial improvement in recognizing ice-cream (sladoled) at 6 and 12 months after implantation, whereas the difference in the ability to identify ice-cream in the time interval between 6 and 12 months was not statistically significant. The word banana (banana) was identified by $32.3 \%$ of examinees at 6 months after implantation, by $22.6 \%$ of examinees at 12 months and by $96.8 \%$ of examinees at 24 months. The difference was not statistically significant only in the period between 12 and 24 months. One examinee alone identified telephone (telefon) at 6 months, 16 examinees at 12 months and 26 examinees at 24 months post-implantation. Statistically tested differences among all analyzed time intervals were significant.

There were no examinees who could identify truck (kamion) at 6 months, while 22 examinees could identify it at 12 months that was an insignificantly smaller number than 28 examinees who could identify truck at 24 months post-intervention (Table 3).

Table 3: Test for identification of the number of syllables in three-syllable words (closed-set).

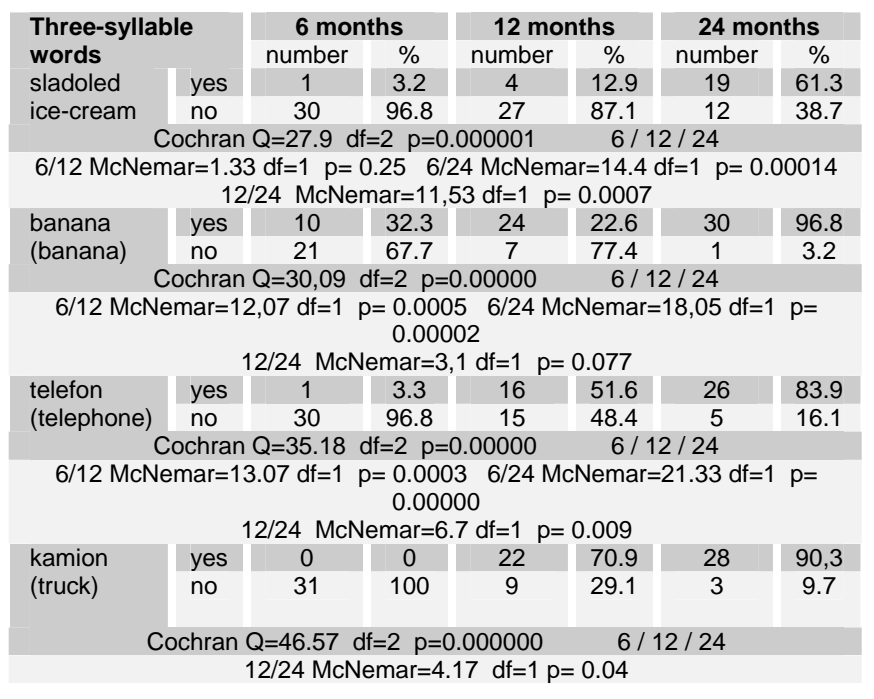

\section{Discussion}

The results obtained with the Cochran's Qtest have confirmed a significant difference in identification of monosyllabic, disyllabic and polysyllabic words in examinees with cochlear implant during the analyzed period of 24 months. There was also a significant difference concerning the time period of utilization of cochlear implant.

McNemar's test has revealed that examinees significantly better identified monosyllabic, disyllabic and polysyllabic words 24 months after implantation in comparison with the period at 12 and 6 months. Also, 12 months after implantation these words were significantly better identified in comparison with the period at 6 months.

During the entire semi-annual period the words have been practiced intensively everyday in rehabilitation sessions using teaching devices.

Monosyllabic words were best identified 24 months following cochlear implantation (by $99 \%$ of examinees). During the same period disyllabic words were identified by $93 \%$ and polysyllabic words by $83 \%$ of examinees.

There was a significant difference related to the period of utilization of cochlear implant. 
Polysyllabic words were least identified (9.7\%) 6 months after implantation; disyllabic words were identified by $21 \%$ of examinees and monosyllabic words were best identified (35\%).

Control analysis 12 months post-implantation showed a significant difference. Polysyllabic words were least identified (40\%), followed by disyllabic (65\%) and monosyllabic words (85\%).

Twenty-four months after implantation identification of all types of words was improved although best results were achieved in recognizing monosyllabic words (99\%), followed by disyllabic (93\%) and polysyllabic words (83\%).

The relation between auditory words and number of spoken words has revealed that the examinee can understand these words, but we did not monitor the auditory perception and its notion and cognitive use [12].

In general, the results suggest that cochlear implants improve speech production to a level that is not possible to be achieved with conventional hearing amplifying aids [13]. These results were to be expected since the hearing aid emphasizes auditory stimuli only in the low sound frequency area, which is not sufficient for creation of auditory picture of all sounds and voices, and hence, the ability to develop verbal communication is very small. Numerous studies report the benefit of cochlear implant use in comparison with conventional amplifying hearing aids. In all spheres of verbal communication the results are statistically better along with reduction in the degree of anxiety and hyper-reactivity in children and depression in adults. In a previous study we examined the verbal evaluation of the same patients when using conventional hearing amplifying aids. The results obtained were poor and, hence, these patients underwent cochlear implantation, which led to significantly better auditory and verbal perception [14].

Better hearing perception and speech production after cochlear implantation have been presented in several studies. Dowell et al. analyzed cochlear implant value in speech production and detected improvement in speech perception in relation to the length of time [15-17].

In 2001 Valimaa TT et al. published their study that comprised 67 patients with cochlear implant. They examined sound perception of the Finnish language using the test of word recognition. Three months following implantation 54\% showed positive results in word recognition, and 24 months following implantation $74 \%$ showed positive results. Six months following implantation 40 subjects were able to recognize some words without lip reading, and 26 of these were able to use the telephone [18]. There results obtained with the same test as ours are in agreement with the results obtained in our study. In 1998 Kiefer $\mathrm{J}$ et al. realized a similar study in 17 implanted subjects. Using the tests for monosyllabic words the recognition scores increased significantly from $9 \%$ pre-operatively to even $42 \%$ post-operatively [19]. Prospective studies, such as that of Gstöttner et al., using tests for syllables, words and sentences recognition of closed-set after cochlear implantation and hearing rehabilitation training demonstrated that $98.7 \%$ of subjects could understand the text [20].

In conclusion, after cochlear implantation there is a substantial improvement of speech production and perception in children with pre-lingual hearing impairment. They show better hearing perception and speech production of monosyllabic and polysyllabic words.

\section{References}

1. Mo B, Lindbaek M, Harris S. Cochlear implants and quality of life: A prospective study. Ear Hear. 2005; 26:186-94.

2. Morera C, Sainz M, Cavalle L, Dela Torre A, Colaboradores: Anderson I, DHaese P. Speech understanding in post-lingual adults with cochlear implants. Acta Otorinolaringol Esp. 2004; 55: 201-5.

3. Ribari O, Kustel M, Faras Z. Cochlear implants in children. Folia Phoniatr Logop. 1996; 48: 127-30.

4. Calvert D, Silverman R. Speech and deafness. Washington, DC: Alexander Graham Bell Association for the Deaf; 1983.

5. Gantz BJ, Tyler R, Woodford G, Tye-Murray N, FraufBertschu $H$. Results of multichannel cochlear implants in congenital and acquired prelinqual deafness in children: Fiveyear follow up. Am J Otol. 1994; 15: 1-8.

6. Esser-Leyding, Anderson I. EARS (Evaluation of Auditory Responses to Speech): an internationally validated assessment tool for children provided with cochlear implants. ORL. 2012; 74: 42-51.

7. Osberger MJ, Todd SL, Berry SW, Robbins AM, Miyamoto RT. Effect of age of onset of deafness on children's speech perception abilities with a cochlear implant. Ann Otol Rhinol Laryngol. 1991;100:883-8.

8. Waltzman S, Cohen N, Shapiro W. Use of a multichannel cochlear implant in the congenitaly and prellinguallu deaf population. Laryngoscope. 1992; 102:395- 399.

9. Sainz M, Skarzynski H, Allum JHJ, HelmsJ, Rivas A, Martin J, Zorowka PG, Phillips L, Delauney J, Brockmeier SJ, Kompis M, Korolewa I, Albergger K, Zwirner P, Van De Heyning P, D'Haese P. Assessment of auditory skills in 140 cochlear implant children using the EARS protocol. ORL.2003; 65: 916.

10. Schram B, Bohnert A, Keilmann A. The prelexical development in children implanted by 16 month compared with normal hearing children. IJPORL. 2009; 73: 1673-81.

11. Erber NP, Alencewicz CM. Audiollogic evaluation of deaf children: J Speech Hear Disord. 1976;41, 256-267.

12. Tye-Murray N. et al. Ascquisition of speech by children who have prolonged cochlear implant experience. J Speech Hear Res. 1995; 38:327-37.

13. Sing AF, Vermeulem AM, Geelen CP, Brokx JP, Vanden Broek $P$. Speech perception performance of children with a cochlear implant compared to that of children with conventional hearing aids. II Results of prellingually deaf children. Acta Otolaryngol.1997;117(5):755-9.

14. Lazarovska V, Topuzovska G, Jovanovska M, Gorgeska B, Delevski B.Fundamental Differences and benefits of hearing behind the ears amplifications and cochlear implant with 
hearing senzoneural impairments. Acta Morphol. 2012; 9(1):56-59.

15. Tobey EA, Angelette S, Murchison C, et al. Speech production performance in children with multichannel cochlear Implants. Am J Otol. 1991;12 Suppl:165-73.

16. Miyamoto RT, Osberger MJ, Todd SL, et al. Speech perception skills of children with multichannel cochlear implants. In: the Proceedings of the Third International Cochlear Implants Conference. Innsbruck, Austria. April 4-7, 1993.

17. Dowell RC, Dawson PW, Dettman SJ, et al. Multichannel cochlear implantation in children: a summary of current work at the University of Melbourne. Am J Otol. 1991;12 Suppl:137- 143.

18. Valimaa TT, Sorri MJ. Speech perception and functional benefit after cochlear implantation: a multicenter survey in Finland. Scan d Audiol. 2001; 30(2): 112- 8.

19. Kiefer J, Von Illberg C, et al. Results of cochlear implantation in patients with severe to profound hearing loss- implications for patient selection. Audiology. 1998; 37, (6): 382-95.

20. Gstoettner W, Hamzavi J, Czerny C. Rehabilitation of patients with hearing loss by cochlear implants. Radiologe. 1997; 37:991-4. 